\title{
Management implications of antelope habitat use in the Kilombero Valley, Tanzania
}

\author{
R. K. B. Jenkins, G. R. Corti, E. Fanning and K. Roettcher
}

\begin{abstract}
High cattle densities, expanding human settlements and the conversion of miombo woodland into farms and teak plantations are threatening wildlife populations in the Kilombero Valley, Tanzania, and conservation research on this internationally important wetland is required as part of an integrated approach to its future management. The effect of land-use change on antelopes (family Bovidae) was investigated by surveying tracks and dung during three seasons over 1999-2000 in an area of mixed land-use. Use of miombo woodland, grassland and farmland habitats by antelopes was highest during the wet season (April-May), probably representing the movements of animals away from the floodplain. Duiker, puku Kobus vardoni and reedbuck Redunca spp. predominantly used the farmland during the wet season, at which time buffalo Syncerus caffer were more common in the miombo woodland. The findings of this study have three main implications for the con-
\end{abstract}

servation of the valley. Firstly, the inadvertent provision of suitable wet season habitats for puku and other smallmedium antelopes by rice farmers could lead to higher levels of illegal hunting, and may increase the potential for conflict between agriculture and wildlife. Secondly, the loss of miombo vegetation will most strongly affect the larger species of antelope (sable Hippotragus niger and waterbuck Kobus ellipsiprymnus), which favour openwoodland habitats; future work should therefore determine levels of habitat use by antelopes in and around maturing teak plantations. Thirdly, any management prescriptions to conserve the Kilombero Valley should include the land on the edge of the floodplain.

Keywords Antelopes, floodplain, Kilombero Valley, management, miombo woodland, Tanzania, teak plantations.

\section{Introduction}

In recent years the expansion of human settlements, livestock grazing areas, illegal hunting, agriculture and commercial forestry has increased the pressure on Tanzania's natural resources (Mwalyosi, 1992; Caro et al. 1998a; UNEP, 1998). All of these land uses can reduce the availability and quality of natural areas and make them less suitable for wildlife. Rapidly growing human populations and settlements may also interfere with migration routes or increase the isolation of protected areas (Newmark, 1996).

Some of Tanzania's partially protected areas are currently unable to provide the levels of management and protection necessary to safeguard their wildlife resources (Caro et al., 1998a; Pelkey et al., 2000). Game

R.K.B. Jenkins ${ }^{1}$ (Corresponding author), G.R. Corti, E. Fanning and K. Roettcher ${ }^{2}$ Society for Environmental Exploration, 50-52 Rivington Street, London, EC2A 3QP, UK.

${ }^{1}$ Present address: Department of Zoology, Tillydrone Avenue, University of Aberdeen, Aberdeen, AB24 2TZ. E-mail: r.jenkins@abdn.ac.uk

${ }^{2}$ Present address: Saadani Conservation Development Programme, c/o GTZ, P.O. Box 1519, Dar es Salaam, Tanzania.

Received 16 May 2001. Revision requested 24 August 2001.

Accepted 1 November 2001
Controlled Areas (GCAs), which have few limits on human activities other than to control trophy hunting, provide only a nominal level of protection (Caro et al., 1998a; Caro, 1999a; Pelkey et al., 2000). In contrast, National Parks and Game Reserves provide the highest levels of protection through prohibiting all forms of human settlements and agricultural activity, but allow trophy hunting (Game Reserves only), research and nonconsumptive tourism (Caro et al., 1998a). Some partially protected areas still contain important wildlife populations (Caro, 1999a), and their close proximity to protected areas, such as National Parks, facilitates seasonal movements of animal populations. The management of partially protected areas that have high population densities of both large mammals and people therefore needs to be addressed to ensure the long-term viability of Tanzania's entire protected area network.

The problems associated with high demand for natural resources by both people and wildlife are often most acute in Tanzania's wetlands, thus making them a high priority for conservation (Kamukala, 1993). Fertile soil, rich fish stocks, abundant woodland resources, and hydroelectric potential all make freshwater wetlands attractive for development (Bakobi, 1993). However, the full economic potential of the wetlands has yet to be realized because limited transport infrastructure, high 
water tables and seasonal inundation impede development. These conditions are also the main reason for the continued existence of the remaining wildlife populations in these wetlands (Bakobi, 1993; Mpemba, 1993). To date, a lack of effective policy, institutional weakness in managing authorities, a bias towards development over conservation, and poor information on key ecological components of the wetlands have hampered management efforts in Tanzania (Bakobi, 1993). However, Tanzania's wetlands are now beginning to receive a higher profile (Kamukala \& Crafter, 1993), a process that culminated in Tanzania joining the Ramsar Convention on Wetlands in August 2000. In 2001, the Kilombero Valley was proposed as Tanzania's third Ramsar site (L. Dinesen pers. comm.).

The inner part of the valley is designated as the Kilombero Game Controlled Area (KGCA). It is home to important populations of large mammals (Table 1), holding c. $75 \%$ of the remaining global population of puku antelope Kobus vardoni (East, 1998; TWCM, 1999), and is therefore an important wetland for antelope (family Bovidae) conservation in East Africa.

Antelopes constitute a large proportion of the mammalian biomass in most of Tanzania's protected areas (Caro et al., 1998a; East, 1998) and they are an important natural resource that provide people with sources of protein, skins and trophies (Caro et al., 1998b; East, 1998). However, many antelope populations are threatened by habitat change, competition with livestock, and excessive off-take by hunters (Caro et al., 1998b; East, 1998; Du Toit \& Cumming, 1999). In the Kilombero Valley, conversion to farmland and extraction of fuelwood combine to put the remaining miombo woodland under increasing pressure, especially near human settlements (Haule, 1997). Furthermore, a new teak Tectona grandis plantation scheme introduced in 1992 by the Kilombero Valley Teak Company (KVTC) aims to convert $8,000-10,000$ ha of miombo woodland into teak plantations. Although the absolute percentage loss of woodland may not constitute a serious threat to wildlife (IIED, 1992), the location of the plantations may interfere with the seasonal movements of large

Table 1 Population estimates $( \pm S E)$ of large mammal species in the Kilombero Game Controlled Area during October 1998 (from TWCM, 1999).

\begin{tabular}{lc}
\hline Species & Population Estimates \\
\hline Elephant & $5,308 \pm 2,151$ \\
Buffalo & $16,778 \pm 12,006$ \\
Reedbuck & $520 \pm 495$ \\
Puku & $66,964 \pm 12,629$ \\
Zebra & $631 \pm 449$ \\
Hippo & $1,262 \pm 755$ \\
\hline
\end{tabular}

mammals. The land between the floodplain and miombo woodland provides the best conditions within the area for agriculture, and is already under pressure from the combined demands of livestock, farming and villages (TWCM, 1999).

The protected area network has long been the primary tool for the conservation of Africa's populations of large mammals (Caro et al., 1998a). More recently, communitybased conservation initiatives, that aim to conserve wildlife whilst at the same time providing benefits to local communities, have been developed (e.g. Kremen et al., 1999; Infield \& Namara, 2001). Although the success of these projects remains equivocal (Adams \& Hulme, 2001; Western, 2001), certain projects in Tanzania have adopted a community-based approach (e.g. Gillingham \& Lee, 1999; Songorwa, 1999). Long-term management of the KGCA and its surroundings should therefore address both the needs of people and animals. However, given the current limitations of Tanzania's GCAs, the increasing human populations around many protected areas, and the inverse relationship between human population density around reserves and the presence of large mammals (Newmark et al., 1994), there is a clear need for increased intervention in the management of the KGCA. The KGCA is a prime example of a wetland, rich in natural resources, which is undergoing changes in land use, and for which a lack of detailed information on the most important biological components is a major impediment to future management plans.

In this study we aim to contribute to the development of a conservation and local community management plan for the KGCA by describing the seasonal variation in habitat use by antelopes. An understanding of how antelopes utilise different habitats is essential for the management of the KGCA because the seasonal inundation of the floodplain is thought to displace large numbers of animals onto the higher land that is used by people. Furthermore, we aim to assess the likely consequences for antelopes of the fragmentation of miombo woodland by new teak plantations.

\section{Methods}

\section{Study area}

The Kilombero Valley is situated in southern-central Tanzania $\left(8^{\circ} 32^{\prime} \mathrm{S} 36^{\circ} 29^{\prime} \mathrm{E}\right)$ and lies adjacent to the Selous Game Reserve and near Mikuni National Park (Fig. 1a). It consists of a seasonally inundated floodplain that is fringed by tracts of miombo woodland, rising to old-block mountains with evergreen forest. The study site, at Mgomba Lenga (Ulanga District, Morogoro Region), consisted of miombo woodland, grassland and rice farms, and was selected by KVTC as suitable for 
(a)

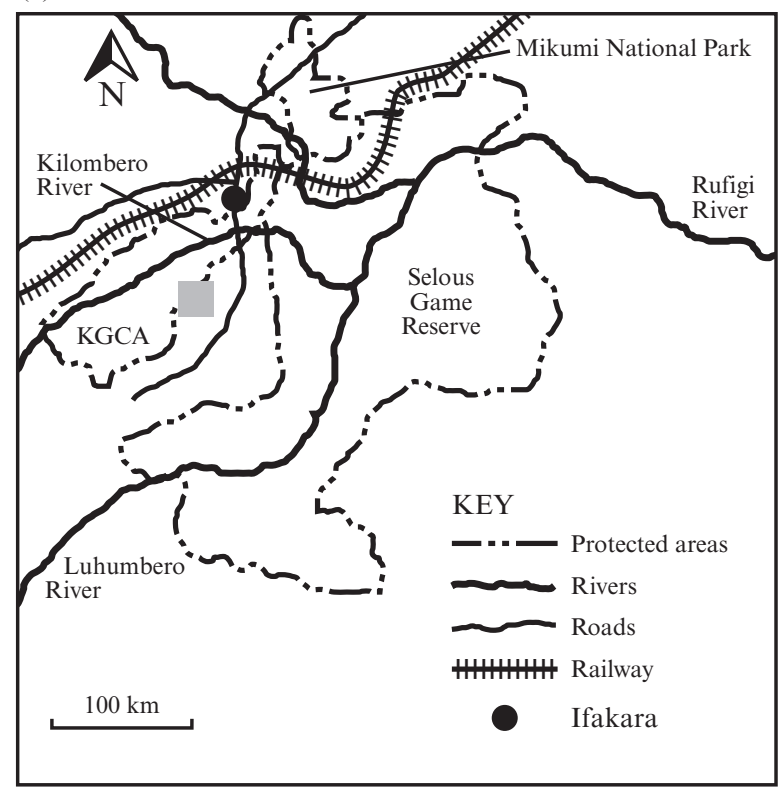

(b)

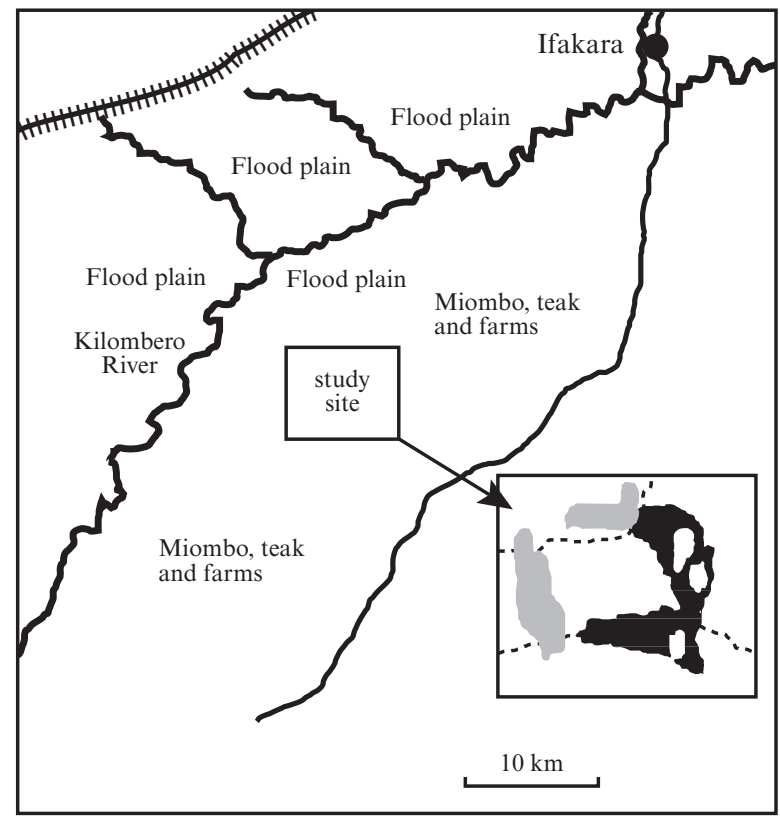

Fig. 1 (a) Map showing the location of the Kilombero Game Controlled Area (KGCA), Mikumi National Park, Selous Game Reserve, major road, railway (Tanzania-Zambia Railway) and watercourse features. The shaded square indicates the position of the study site. (b) Map of the study site at Mgomba Lenga, Ulanga District, Tanzania. Miombo woodland (white), grassland (black), farmland habitats (grey) and trails/tracks.

teak plantations because of its pedology, topography and altitude (IIED, 1992). This study site was $<5 \mathrm{~km}$ from the edge of the floodplain and was therefore identified as a potential wet season refuge for wildlife.
The area was classified into three habitat types (Fig. 1b) based on land use and vegetation:

- Miombo woodland: raised areas of vegetation, consisting mainly of Brachystegia spiciformis trees, with Holarrhena pubescens and Diplorynchus condylocarpon also present.

- Grassland: open-grassland depressions (known as mbugas) with trees of Combretum spp., Pericopsis spp. and Lonchocarpus spp.

- Farmland: low-lying areas cultivated for rice. These areas were dry and accessible between October and December, but farming activity and crops limited access by the survey teams from February to May. During this period surveys were undertaken on the edge of the farmland.

Parts of the miombo woodland and grassland in our study area were designated for clearance and teak planting during August 2000. As part of a planned, long-term assessment of the impact of clear felling and teak planting on antelopes and other wildlife, the current study was designed to describe the antelope assemblage in the area before the fragmentation and loss of woodland and grassland habitats. For the purpose of this study we divided the period into three seasons, which were broadly consistent with major rainfall patterns and associated changes in vegetation. Three-monthly mean rainfall recorded by KVTC in Ifakara was $272 \mathrm{~mm}$ for period one (September-November 1999), 1,089 mm for period two (December 1999-February 2000) and 1,509 $\mathrm{mm}$ for period three (March-May 2000). Transect sample sizes were 40, 40 and 20 in miombo woodland, grassland and farmland respectively in period one, 62, 62 and 66 in period two and 49,27 and 33 in period three.

\section{Track surveys}

Survey periods were 6-8 weeks apart. A rapid survey technique was used to compare the frequency of use by antelopes of different habitats. Surveys were undertaken using a stratified random design, with the numbers of line transects in each habitat (woodland $n=151$, grassland $n=129$, farmland $n=119$ ) being approximately representative of the amount of that habitat in the study area, as estimated from 1:50,000 maps, aerial photographs and walking in the area. Line transects using counts of tracks and signs, rather than observations of animals, were used because: (1) Large mammals in the KGCA woodlands are wary of people and do not allow close approach (R.K.B.J., G.C.R. \& K.R., pers. obs.), consistent with other unprotected areas in Tanzania, where game species are more likely to flee from a vehicle in areas where they are hunted compared to National Parks (Caro, 1999a, b), (2) there was no extensive track 
system suitable for vehicle access, and (3) track and sign counts allowed field surveys to be conducted independently of antelope diurnal activity patterns, whereas direct counts are typically restricted to early morning. The need to use cost effective and non-intrusive methods to monitor secretive, cryptic or threatened mammals has long been recognized (Kendall et al., 1992), and these methods continue to be used (e.g. Virgós, 2001).

Transects were $200 \mathrm{~m}$ apart and were marked with a $100 \mathrm{~m}$ length of rope labelled at $20 \mathrm{~m}$ intervals. At the starting point for each transect a wooden baton was thrown backwards over the observer's head to determine the direction of the transect line, which was laid out taking care not to disturb the conditions underfoot. Two observers slowly walked the transect line and searched $1.5 \mathrm{~m}$ on each side (i.e. a width of $3 \mathrm{~m}$ ) for tracks and dung or pellet groups of buffalo Syncerus caffer, duiker (Harvey's red duiker Cephalophus harveyii, Natal red duiker C. natalensis and the common duiker Sylvicarpa grimmia are all present in the Selous ecosystem; UDDNR, 1997; East, 1998), puku Kobus vardoni, reedbuck (southern reedbuck Redunca arundinum and bohor reedbuck R. redunca), sable Hippotragus niger and waterbuck Kobus ellipsiprymnus. The observers remained close to the line at all times, leaving it only to record a sign first seen from the transect line. Ulanga District Game Office scouts (listed in acknowledgements) verified all identifications. All surveyors were familiar with the tracks and faeces of the study animals from previous research. Visual confirmations were made of all species to confirm their presence at the site.

A relative track index was calculated by recording track presence or absence for each antelope taxon in the five $20 \mathrm{~m}$ sections of the transect line. The relative track index therefore ranged from zero (no tracks over $100 \mathrm{~m}$ ) to five (tracks in each $20 \mathrm{~m}$ section). This method allowed us to rapidly survey areas that had been heavily used by antelopes without having to count all individual tracks. Each dung pile or pellet group within the $3 \mathrm{~m}$ strip was counted to give a total per $100 \mathrm{~m}$. Whenever possible, dung and track observations were aged by the game scouts as either 'since last survey' or 'before last survey', allowing exclusion of signs that were present during the previous survey.

\section{Data Analysis}

Each line transect was treated as an independent replicate. We did not make direct comparisons between taxa (i.e. species $a$ is more abundant than species $b$ because we found more dung or tracks of species a) because defecation rates can vary between species. We assumed that differences in signs were a true representation of the use of each habitat and that differences in the detectability of signs between habitats were negligible. Non-parametric techniques were used to analyse the data, which were not normally distributed (SPSS, 1995).

\section{Results}

Field identification of the signs of small antelopes can sometimes be difficult. It was not possible to determine which of the three species of duiker produced 'duiker' tracks, or which of the two species of reedbuck produced 'reedbuck' tracks. It may also have been possible to confuse reedbuck and bushbuck Tragelaphus scriptus tracks and pellet groups, although no bushbuck were observed in the area. For the purpose of this study, differences between similar-sized species, often of the same genus, were less important than differences between ecologically distinct species. We therefore considered reedbuck and bushbuck to be synonymous and classed them as 'reedbuck' and grouped all 'duiker' species together.

Under most conditions we would expect pellet groups to last longer than tracks because the latter are more susceptible to being disturbed by wind and rain, or may be covered by new tracks. There is little consistency between significant differences for track score and pellets, apart from puku, for which the abundance of pellet groups and tracks was significantly different between habitats (Table 2). Overall, tracks revealed more significant differences than pellet counts. In general, more tracks were found in the wet season, a period when soft ground conditions facilitated the retention of tracks.

Significantly more signs from five out of the six taxa were found during the wet season, but use of the three habitats varied among taxa. Use of the area by buffalo was greatest in the wet season, when observations were most frequently made in grassland and miombo woodland (Fig. 2a \& g). However, this result was only significant for the relative track score because large variation in dung counts within season and habitat obscured any other effects (Table 2, Fig. 2a). Based on the relative track score, use of the areas by duiker was significantly higher in the wet season (Table 2), when both farmland and miombo woodland were used (Fig. 2 h). Puku relative track score varied significantly during the study, with the highest abundance of signs recorded from farmland during the wet season (Table 2, Fig. 2i). Puku also showed significant variation in pellet abundance between habitats, with farmland again the most frequently used (Fig. 2c). Significant differences between habitat type 
Table 2 Comparisons between the abundance of pellets/dung and track scores for six antelope taxa between three seasons from three habitats in the Kilombero Valley, Tanzania. All tests were KruskalWallis and, as multiple comparisons are made, significance levels have been adjusted using the Bonferonni method (Fry, 1996). ${ }^{*} P<0.002$.

\begin{tabular}{llcc}
\hline & & \multicolumn{2}{c}{$H$ values $/(2 \mathrm{df})$} \\
\cline { 3 - 4 } Species & Abundance Measure & Season & Habitat \\
\hline \multirow{2}{*}{ Buffalo +} & Track score & $85.6^{*}$ & $23.7^{*}$ \\
& Dung abundance & 5.1 & 2.9 \\
Duiker $+\ddagger$ & Track score & $49.0^{*}$ & 13.7 \\
& Pellet group abundance & 2.7 & 8.2 \\
Puku + & Track score & $36.9^{*}$ & $43.8^{*}$ \\
& Pellet group abundance & 16.2 & $26.0^{*}$ \\
Reedbuck $+\#$ & Track score & $41.1^{*}$ & $20.0^{*}$ \\
Sable + & Pellet group abundance & 10.8 & 9.8 \\
& Track score & 3.0 & 7.3 \\
Waterbuck + & Pellet group abundance & 1.3 & 7.1 \\
& Track score & $106.0^{*}$ & $20.1^{*}$ \\
& Pellet group abundance & 4.2 & 5.5 \\
\hline
\end{tabular}

+ 2000 IUCN Red List category (Hilton-Taylor, 2000) is Lower Risk: conservation dependent.

$\ddagger$ Cephalophus harveyii and C. natalensis are categorized as Lower Risk: conservation dependent; Sylvicarpa grimmia does not have a Red List status

\#Redunca arundinum and $R$. redunca

and season were also recorded for relative track scores of waterbuck, with highest levels of use from miombo and grassland during the wet season (Table 2, Fig. 21). Differences were not significant for sable (Table 2, Fig. 2e $\& \mathrm{k})$.

If differences in the detectability of signs were solely caused by variation in vegetation structure between habitats, we would expect the open farmland to have always produced the highest abundance of signs. This was not the case, and only puku, duiker and reedbuck signs were most abundant in the farmland. Similarly, the leaf litter and understorey in the miombo woodland would be expected to reduce detectability, but the signs of sable, buffalo and waterbuck were most frequently recorded from the miombo woodland. We therefore conclude that our results are not an artifact of detectability, but we nevertheless advocate a degree of caution when interpreting the results.

\section{Discussion}

Because of their importance to both people and wildlife, the conservation of Tanzania's freshwater wetlands is becoming a national priority (Kamukala \& Crafter, 1993). The Kilombero Valley was identified in 1993 as a wetland in need of conservation, management and wise multiple use (Kamukala \& Crafter, 1993), but no concerted effort was made to manage the area. More recently the valley's profile has been raised by its proposal as a Wetland of International Importance under the Ramsar Convention on Wetlands (L. Dinesen pers. comm.), but lack of basic data on the wildlife communities of the valley continues to hinder the development of strategic management plans.

In this study we found that antelopes used habitats on the edge of the floodplain during the wet season (April and May), drawing attention to the importance of this zone. It is believed locally that lion Panthera leo, zebra Equus burchelli, buffalo and puku leave the floodplain in the wet season for the drier land at the periphery (UDDNR, 1997). The relative track scores from our survey corroborated this belief for both puku and buffalo. Although we cannot prove that the puku and buffalo originated from the floodplain, it is unlikely that the puku came from elsewhere, and both species are present on the floodplain in large numbers during the dry season (Table 1).

Evidence of reedbuck, duiker and puku, although recorded from all habitats, was most commonly found in farmland. Antelopes are considered pests in these situations and can cause severe damage to crops. Buffalo and waterbuck also used farmland and may be responsible for some crop damage, although both of these species used the grassland and woodland habitats more frequently than the farms.

Our results indicate that conversion of the study area to teak plantations will reduce the habitat availability for sable, waterbuck, buffalo and reedbuck through the loss of grassland and miombo woodland. Although sable showed an apparent preference for woodland and grassland habitats, with more signs found in the wet season, it was the only taxon for which there were no significant differences in signs between habitat or season.

The patterns of habitat use shown by the antelopes in this study have five important implications for the management of the KGCA and its surroundings:

\section{The need for woodland surveys}

Conservation monitoring in Tanzania traditionally uses aerial counts of open savanna habitats to survey mammal populations and to detect changes in population sizes (e.g. TWCM, 1995, 1999). Whilst these surveys are a vital tool in conservation management, there is a growing appreciation of the need to carry out ground surveys in wooded habitats in order to adequately sample species infrequently recorded from the air or from roads (Caro, 1999c; Fischer \& Linsenmair, 2001). Our study shows how data that would be unobtainable from the air can be collected in a relatively short period of time. 
a) Buffalo dung



d) Reedbuck pellet groups

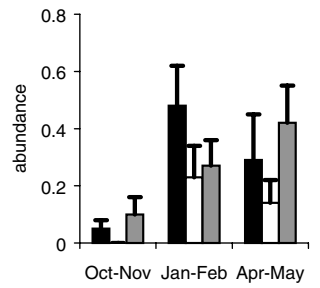

g) Buffalo tracks

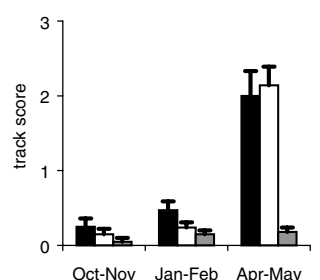

j) Reedbuck tracks



b) Duiker pellet groups

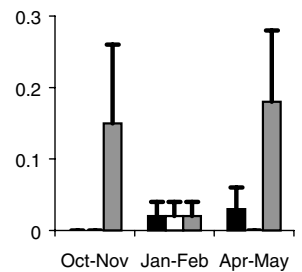

e) Sable pellet groups

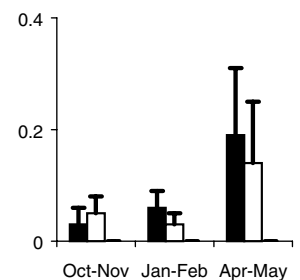

h) Duiker tracks



k) Sable tracks



c) Puku pellet groups

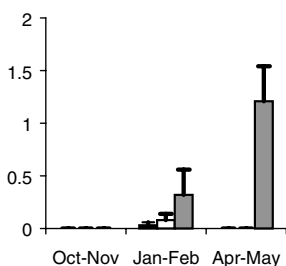

f) Waterbuck pellet groups

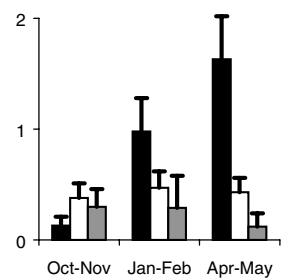

i) Puku tracks

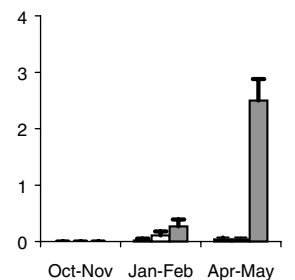

I) Waterbuck tracks

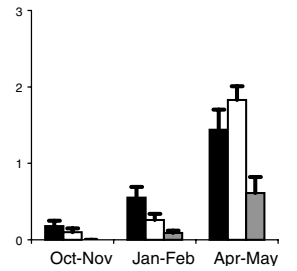

Fig. 2 (a to 1) Mean abundance (+1 SE) of pellet/dung counts and relative track score per $100 \mathrm{~m}$ for six antelope taxa in three seasons from the Kilombero Valley from October 1999 to May 2000 (April-May is the wet season). See Table 2 for statistical significance. Miombo woodland (white), grassland (black) and farmland (grey).

\section{Conservation of puku}

Puku are categorized as Lower Risk: conservation dependent on the 2000 IUCN Red List (East, 1998; Hilton-Taylor, 2000), and the isolation of approximately $75 \%$ of the remaining population in the Kilombero Valley, a poorly protected area that is subject to increasing human influence, is a cause for concern. Although the most recent aerial surveys indicate that the population is stable (TWCM, 1999), the impacts of illegal hunting and habitat fragmentation remain unknown. Whilst puku in the Kilombero Valley are restricted to the floodplain grasslands during the dry season (TWCM, 1999), our study demonstrates that in the wet season they undergo small-scale movements into other habitats, including rice farms. It is likely that puku are more vulnerable to illegal hunting in these open farmland areas than in the naturally vegetated, wet depressions that they probably used before the land was converted into agriculture. The annual movements of puku away from the wetter parts of the floodplain will result in their continued reliance on marginal habitats, and although the establishment of rice farms near the floodplain continues to provide viable wet season habitat for puku, close proximity to human settlements is rarely favourable for megafauna (Newmark 1996; Fischer \& Linsenmair, 2001; Harcourt et al., 2001), and the situation requires further scrutiny.

\section{Wildlife and agriculture conflicts}

Damage to crops by wildlife is a serious problem in many parts of Africa, especially where wildlife populations occur close to concentrations of agriculture (e.g. 
Parry \& Campbell, 1992; Naughton-Treves, 1998; Infield \& Namara, 2001). Crop damage by herbivores is also a growing problem in the Kilombero Valley because farms are moving closer to the floodplain (Haule, 1997). In a questionnaire survey of farmers in five villages near the study area, puku and buffalo were the antelopes considered to cause the most damage to rice and maize crops (Haule, 1997). This results in economic loss to individual farmers (and sometimes physical injury) and crop protection measures that can result in the killing of antelopes. Newmark et al. (1994) advocated that compensation programmes for loss of livestock and crops, and land-use planning and zoning should be used to address the problem of conflicts between wildlife and agriculture in Tanzania. Our results indicate that the management of the zone between the hills and floodplain is vital, and there are new initiatives underway that recognize this (L. Dinesen pers. comm.). To this end, the promotion of land-use practices that maintain low human population densities on land adjacent to areas rich in wildlife is a sensible goal (Newmark et al., 1993).

\section{Management of teak plantations}

Apart from a large sugar plantation, the Kilombero Valley was relatively devoid of organized agricultural development until the initiation of the new teak plantation programme in 1992. The establishment of an all-weather road network in areas that were previously only accessible by foot may profoundly alter the local environment by improving access for illegal hunters and pastoralists and by facilitating the further expansion of farmland (Bennett \& Robinson, 2000). Conversion of miombo woodland and grassland into teak plantations will result in habitat loss and fragmentation, and use of these habitats by waterbuck, buffalo and sable probably make these species the most vulnerable to such habitat perturbation. Before the effects of fragmentation (Newmark, 1996; Laurance, 1997) in the Kilombero Valley can be predicted, the use of teak by wildlife over the full life of a plantation needs to be understood, and research on antelope home range and diet is required. Preliminary work in the Kilombero Valley has shown that some large mammal species regularly use teak plantations (Hinde et al., 2001), but species composition varied according to the age of the trees and the distance to the floodplain (Jenkins et al., unpub. data). In India conversion of natural forests into teak plantations did not affect the species richness of small mammals or ungulates, but overall population densities were usually reduced (Karanth \& Sunquist, 1992; Chandrasekar-rao \& Sunquist, 1996). Teak plantations can therefore provide useful habitat for wildlife, especially over a mosaic of natural vegetation and plantations of different ages, and the policy of KVTC to develop small ( $<50$ ha) plantations of variable age, surrounded by areas of natural vegetation, may be more favourable to wildlife than a few large teak plantations. The oldest teak plantations in the Kilombero Valley are approaching 10 years old, but conclusions about the impact of these plantations on the antelope community are preliminary because the harvest age of the trees is $30-40$ years. As managers of large-scale land-use change in an internationally important wetland, it is important for KVTC to manage its teak plantations for the benefit of both local human and wildlife communities. Early results are encouraging, with co-operation between the Kilombero Valley Integrated Environmental Management Programme and KVTC in the ecological assessment of potential plantation sites with a view to conserving those that are of the most biological importance.

\section{Conservation and wise use of the Kilombero Valley}

Aerial surveys of agricultural activity, settlements and cattle have revealed that the highest intensity of human activity in the KGCA occurs at its edge, whilst puku, buffalo and elephant dry season distributions are concentrated in the centre of the KGCA (TWCM, 1999). Rodgers (1984) advocated upgrading the core of the KGCA to a Game Reserve, to protect the puku population. Whilst this approach would improve conservation of the pukus' dry season habitat, it does not address the degradation of the edge of the floodplain which, as our study has demonstrated, is a key habitat during the wet season. Any future proposal will have to address both the need of the animals to leave the floodplain in the wet season and the legitimate requirements of the human population.

\section{Conclusions}

Based on the abundance of tracks and signs of six antelope taxa, this study has shown that use of all habitats in the study area was greatest during the wet season. Evidence of habitat use by large species, such as waterbuck and buffalo, was significantly higher in woodland and grassland areas. In contrast, smaller antelopes predominantly used farmland and grassland. However, all antelopes used woodland and grassland at some stage during the year, and further agricultural development of the study area, leading to more farms and teak plantations, and improved roads, will therefore threaten the entire antelope community. The seasonal variation in antelope abundance and the patterns of habitat use have three main implications for the conservation of the valley and its wetlands. Firstly, the inadvertent provision of suitable wet season habitats for 
puku and other small-medium antelopes by rice farmers may lead to higher levels of illegal hunting and increase the potential for conflict between agriculture and wildlife. Secondly, loss of miombo woodland habitat in this area, whether to teak plantations or other land uses, will affect large species such as waterbuck and buffalo the most; future work is required to determine levels of habitat use by antelope in and around maturing teak plantations, potential use of which may mitigate the loss of woodland. Thirdly, any management prescriptions to conserve the Kilombero Valley should include the land on the edge of the floodplain. As this area provides a wet-season refuge for floodplain species, its conservation should be an integral feature of the future management of the Kilombero Valley.

\section{Acknowledgements}

We would like to thank the personnel at the Ulanga District Department of Natural Resources and the Kilombero Valley Teak Company for their assistance. Particular thanks to Chris Bekker, Warren Rance, Crispin Golding, Rashid Matanda and Kennedy Haule (KVTC); Edward Mlaponi, Salum Musa, Peter Msumgano, Jacob Ndimbo, Haruni Miassa and Israel Manselli (Ulanga game scouts); Octavian Ngwamba (Catchment Forestry Project), Posi Luvili, Francis Mhaiki, Rashid Limaga and all Research Assistants for help in the field. Alan Rodgers, John Chettleborough and Lars Dinesen provided valuable comments on earlier drafts. This work formed part of the Frontier-Tanzania Savanna Research Programme (collaboration between the University of Dar es Salaam, Tanzania and the Society for Environmental Exploration, UK) and was funded by the National Lottery Charities Board (UK), KVTC and the Society for Environmental Exploration.

\section{References}

Adams, W.M. \& Hulme, D. (2001) If community conservation is the answer in Africa, what is the question? Oryx, 35, 193-201.

Bakobi, B.L.M. (1993) Conservation of wetlands of Tanzania. In Wetlands of Tanzania. (eds G.L. Kamukala \& S.A. Crafter), pp. 15-27. Proceedings of a Seminar on the Wetlands of Tanzania, Morogoro, Tanzania, 27-29 November, 1991. IUCN, Gland, Switzerland, and Cambridge, UK

Bennett, E.L. \& Robinson, J.G. (2000) Hunting of Wildlife in Tropical Forests: Implications for Biodiversity and Forest Peoples. The World Bank Environment Department, Washington, DC, USA

Caro, T.M. (1999a) Densities of mammals in partially protected areas: the Katavi ecosystem of western Tanzania. Journal of Applied Ecology, 36, 205-217.

Caro, T.M. (1999b) Behaviour and demography of African mammals subject to exploitation. Biological Conservation, 91 91-97.
Caro, T.M. (1999c) Conservation monitoring: estimating mammal densities in woodland habitats. Animal Conservation, 2, 305-315

Caro, T.M., Pelkey, N., Borner, M., Campbell, K.L.I., Woodworth, B.L., Farm, B.P., Kuwai, J.O., Huish, S.A. \& Severre, E.L.M. (1998a) Consequences of different forms of conservation for large mammals in Tanzania: preliminary analyses. African Journal of Ecology, 36, 303-320.

Caro, T.M., Pelkey, N., Borner, M., Severre, E.L.M. Campbell, K.L.I., Huish, S.A., Kuwai, J.O., Farm, B.P. \& Woodworth, B.L. (1998b) The impact of tourist hunting on large mammals in Tanzania: an initial assessment. African Journal of Ecology, 36, 321-346.

Chandrasekar-rao, A. \& Sunquist, M.E. (1996) Ecology of small mammals in tropical forest habitats of southern India. Journal of Tropical Ecology, 12, 561-571.

Du Toit, J.T. \& Cumming, D.H.M. (1999) Functional significance of ungulate diversity in African savannas and the ecological implications of the spread of pastoralism. Biodiversity and Conservation, 8, 1643-1661.

East, R. (1998) African Antelope Database 1998. IUCN/SSC Antelope Specialist Group Report. IUCN, Gland, Switzerland.

Fischer, F. \& Linsenmair, K.E. (2001) Decreases in ungulate population densities. Examples from the Comoé National Park, Ivory Coast. Biological Conservation, 101, 131-135.

Fry, J.C. (1996) Biological Data Analysis. A Practical Approach. Oxford University Press, Oxford, UK.

Gillingham, S. \& Lee, P.C. (1999) The impact of wildlife related benefits on the conservation attitudes of local people around the Selous Game Reserve, Tanzania. Environmental Conservation, 26, 218-228.

Harcourt, A.H., Parks, S.A. \& Woodroofe, R. (2001) Human density as an influence on the species/area relationships: double jeopardy for small African reserves? Biodiversity and Conservation, 10, 1011-1026.

Haule, K.S. (1997) Wildlife prospects in the Kilombero Game Controlled Area, Tanzania. Traditional vs state management. MSc thesis, Centre for International Environment and Development Studies Noragric, Agricultural University of Norway.

Hilton-Taylor, C. (compiler) (2000) 2000 IUCN Red List of Threatened Species. IUCN, Gland, Switzerland, and Cambridge, UK.

Hinde, R.J., Corti, G.R., Fanning, E. \& Jenkins, R.K.B. (2001) Large mammals in miombo woodland, evergreen forest and a young teak plantation in the Kilombero Valley, Tanzania. African Journal of Ecology, 39, 318-321.

IIED (1992) The Environmental Impact of the Proposed Kilombero Valley Hardwood Project, Tanzania. An Assessment of a Project Proposed by the Commonwealth Development Corporation. The International Institute for Environment and Development (IIED), London and The Institute of Resource Assessment (IRA), University of Dar es Salaam, Tanzania.

Infield, M. \& Namara, A. (2001) Community attitudes and behaviour towards conservation: an assessment of a community conservation programme around Lake Mburo National Park, Uganda. Oryx, 35, 48-60.

Kamukala, G.L. (1993) An overview and scope of Tanzanian wetlands. In Wetlands of Tanzania (eds G.L. Kamukala \& S.A. Crafter), pp. 9-15. Proceedings of a Seminar on the Wetlands of Tanzania, Morogoro, Tanzania, 27-29 
November, 1991, IUCN, Gland, Switzerland, and Cambridge, UK.

Kamukala, G.L. \& Crafter, S.A. (eds) (1993) Wetlands of Tanzania. Proceedings of a Seminar on the Wetlands of Tanzania, Morogoro, Tanzania, 27-29 November, 1991, IUCN, Gland, Switzerland, and Cambridge, UK.

Karanth, K.U. \& Sunquist, M.E. (1992) Population structure, density and biomass of large herbivores in the tropical forests of Nagarhole, India. Journal of Tropical Ecology, 8, 21-35.

Kendall, K.C., Metzgar, L.H., Patterson, D.A. \& Steele, B.M. (1992) Power of sign surveys to monitor population trends. Ecological Applications, 2, 422-430.

Kremen, C., Razafimahatratra, V., Guillery, R.P., Rakotomalala, J., Weiss, A. \& Ratsisompatrarivo, J.S. (1999) Designing the Masoala National Park in Madagascar based on biological and socioeconomic data. Conservation Biology, 13, 1055-1068.

Laurance, W.F. (1997) Responses of mammals to rainforest fragmentation in tropical Queensland: a review and synthesis. Wildlife Research, 24, 603-612.

Mpemba, E.B. (1993) Wildlife resources and tourism in the wetlands of Tanzania. In Wetlands of Tanzania (eds G.L. Kamukala \& S.A. Crafter), pp. 61-67. Proceedings of a Seminar on the Wetlands of Tanzania, Morogoro, Tanzania, 27-29 November, 1991, IUCN, Gland, Switzerland, and Cambridge, UK.

Mwalyosi, R.B.B. (1992) Land-use changes and resource degradation in south-west Masailand, Tanzania. Environmental Conservation, 19, 145-152.

Naughton-Treves, L. (1998) Predicting patterns of crop damage by wildlife around Kibale National Park, Uganda. Conservation Biology, 12, 156-168.

Newmark, W.D., Leonard, N.L., Sariko, H.I. \& Gamassa, D.M. (1993) Conservation attitudes of local people living adjacent to five protected areas in Tanzania. Biological Conservation, 63, 177-183.

Newmark, W.D., Manyanza, D.N., Gamassa, D.M. \& Sariko, H.I. (1994) The conflict between wildlife and local people living adjacent to protected areas in Tanzania: human density as a predictor. Conservation Biology, 8, 249-255.

Newmark, W.D. (1996) Insularization of Tanzanian parks and the local extinction of large mammals. Conservation Biology, 6, 1549-1556.

Parry, D. \& Campbell, B. (1992) Attitudes of rural communities to animal wildlife utilization in Chobe enclave and Mababe depression, Botswana. Environmental Conservation, 19, 245-252.

Pelkey, N.W., Stoner, C.J. \& Caro, T.M. (2000) Vegetation in Tanzania: assessing long-term trends and effects of protection using satellite imagery. Biological Conservation, 94, 297-309.

Rodgers, W.A. (1984) Status of the puku (Kobus vardoni Livingstone) in Tanzania. African Journal of Ecology, 22, 117-125.
Songorwa, A.N. (1999) Community-based wildlife management (CWM) in Tanzania: are the communities interested? Word Development, 12, 2061-2079.

SPSS (1995) SPSS for windows, Release 6.1.2. SPSS Inc., Chicago, USA.

TWCM (1995) Aerial Survey of the Selous Game Reserve, Mikumi National Park, and Surrounding Areas. Dry Season 1994. Unpublished report, Frankfurt Zoological Society, Arusha, Tanzania.

TWCM (1999) Aerial Census: Selous Game Reserve, Mikumi National Park and Surrounding Areas. Dry Season. October 1998. TWCM/FZS Wildlife Survey Report. Unpublished report, Frankfurt Zoological Society, Arusha, Tanzania.

UDDNR (1997) Wildlife and Forestry Inventory Report. Rainy season, April-May 1997. Unpublished report, Mahenge, Tanzania.

UNEP (1998) Tanzania. Country Study on Biological Diversity. Unpublished report to the Government of the United Republic of Tanzania, by the United Nations Environment Programme, the Global Environmental Facility, and the Norwegian Agency for Development Co-operation.

Virgós, E. (2001) Relative value of riparian woodlands in landscapes with different forest cover for medium-sized Iberian carnivores. Biodiversity and Conservation, 10, 1039-1049.

Western, D. (2001) Taking the broad view of conservation - a response to Adams and Hulme. Oryx, 35, 201-204.

\section{Biographical sketches}

Richard Jenkins is a graduate in ecology from the University of East Anglia (UK) and completed his $\mathrm{PhD}$ at Cardiff University (UK). He has conducted research in African wetlands, rainforests and savannas, and is currently coordinating an ecological training project on insectivorous bats in Madagascar.

Graham Corti is a graduate from the University of Southampton (UK) and has been working in the Kilombero Valley since 1998. He is currently studying the ecology of the puku antelope for his $\mathrm{PhD}$.

Eibleis Fanning has been involved in international conservation efforts through volunteer-based projects for over 10 years. As Director of the Society for Environmental Exploration she oversees projects in Tanzania, Madagascar and Vietnam.

Kirsten Roettcher has an MSc in Land and Water Management from Cranfield University (UK). She is currently a Project Officer on the Wildlife Programme of the German Agency for Technical Co-operation in Dar es Salaam, Tanzania. 